\title{
Establishment and Improvement of the Assessment Mechanism of Local Party and Government Cadres
}

\author{
Hai $\mathrm{Hu}^{1, \mathrm{a}}$ \\ College of Marxism, Sichuan Agricultural University 211, Huimin Road, Wenjiang District, cheng'du \\ City 611130, China \\ E-mail: huhai119@163.com
}

Key words: Party and Government Leading Cadres; Assessment Mechanism

\begin{abstract}
Leading cadres is the socialist modernization of our country the main responsibility in the institutional framework, follow the rule of reason, with the rational spirit through the selection of the main assessment team, set the evaluation index with rational principle, the implementation of justice the purpose of the assessment program, is to promote the building of leading cadres to improve the team, team quality plays an important role. To build a well-off society in an all-round way and build socialism with Chinese characteristics, cadres are the decisive factor. Therefore, to establish and perfect the cadre evaluation system, to further innovate the evaluation mechanism, establish and improve the assessment content, methods, and actively build scientific evaluation system of leading cadres, with ten points of great significance to the construction of cadres is full of vitality and activity.
\end{abstract}

\section{Innovative Assessment Mechanism, in Accordance with the Classification of Leading Cadres of the Party and Government Assessment}

The establishment of a scientific cadre classification and classification management system is the objective requirement of scientific, professional and modern social management. Only in accordance with the classification of the requirements of scientific management, depending on the nature of work, with different occupation characteristics and different growth of the personnel to implement the management measures, in order to adapt to the social management more scientific, modern and professional requirements. It should be said that in the past, we are still lagging behind in the methods, contents and other aspects of the cadre inspection work, and it is difficult to adapt itself to the new situation and new changes. In view of some problems existing in the assessment of cadres, we should strengthen the assessment work in the following aspects, and form corresponding systems and operating mechanisms.

In the improvement of assessment methods, we should strive for various forms, different levels and rich means. In the new situation, only by exploring and seeking new means and new methods can we prevent and overcome the limitations of the present assessment work. Specifically, first, we use the method of classification investigation. In accordance with different positions, different work nature, from different angles, different sides of the different assessment objects for comprehensive inspection. Two is the multi-purpose dynamic examination method, to inspect the object work content inspection, but also must work outside "the circle of life", "the social circle" carries on the inspection understanding. Three is the use of reverse assessment methods. In the investigation, when talking about individual shortcomings in the current job unit of the cadres, there are often worries and shortcomings, and are reluctant to talk about them. Therefore, in the case of conditions permit, you can go to the original unit of cadres to understand, at this time most of the speakers can speak freely, speak bluntly.

In the improvement of the content of the investigation, we should strive to make the elements clear, the content specific, and intuitive and clear. The cadre assessment aims to understand and 
grasp the situation of cadres, for promotion, demotion, dismissal, rewards and punishment education cadre exchange rotation to provide the reliable basis and reference. Therefore, in the assessment, first, we should highlight the content of "Lian Lian"; two, we should increase the content of "individuality"; three, we should enrich the content of "insufficient"; four, we should examine the content of "history".

In the setting of assessment standards, we should strive to be scientific, standardized, objective and impartial, and to measure and evaluate. In the formulation of assessment standards, we should pay attention to grasp several relations: first, to accurately grasp the relationship between morality and talent; two, to correctly understand the relationship between seniority and ability, educational background and level. That is to say, the level of judgment depends on the educational background, the ability to judge and the qualifications. Three is the correct distinction between performance and potential performance; four is the correct distinction between the process and the results of the relationship.

In the implementation of assessment responsibilities, and strive to clear responsibilities, responsibility to people, rewards and punishments clear. When assessing responsibility system, it is necessary to make clear the principle of who examines and who is responsible. Two, we must adhere to the principle of fair and reasonable, lenient and proper. Three is to carry out the principle of separating the responsibility subject from the subject of investigation. The four is to adhere to the principle of operability. Assessment responsibility system must be thorough, detailed and clear, and at the same time simple and easy, so as to ensure the implementation of the responsibility system. The five is to be in line with the principle of.

\section{Innovation Index System, the Establishment of Scientific, Reasonable, Fair and Impartial Party and Government Leading Cadres Assessment Indicators}

All of the evaluation system, both the method of assessment content, methods, or assessment results of evaluation and application are carried out around the entire evaluation index, the lack of it, will make the assessment work become a source of water, without trees. Therefore, it occupies a very important position in the entire assessment system, so it is very critical.

First, work out overall goals. This general objective mainly refers to the term objectives of the organizational system. It includes definite and uncertain goals, and phased goals that should be completed during the term of office. At the same time also includes integrity should reflect the target for the completion of tasks. The total goal, then according to the division of team members and their respective responsibilities, to decompose the overall goal of the common goals and functions of goals and milestones, implementation of each member, make concrete.

The second is to determine the evaluation criteria. If you have a goal, you have to have standards and no standards to evaluate. It is difficult to determine the good or bad of the work. This standard must be specific, to a certain degree of requirements. The basic quality and performance should be based on the excellent, competent, basically competent and incompetent four grades should have done people develop specific standards for each other, in order to set at the time of assessment, and prevent the qualitative problems difficult, qualitative hard. Only when the examination standards are materialized and rationalized can the real sense of fairness and justice be achieved. Otherwise, continue to use the present qualitative evaluation method, not only the inspection team is difficult to grasp, and the conclusions I will not be convinced, in fact, this situation often occurs.

Third, it is necessary to formulate a reward and punishment program which is reasonable and conducive to stimulating the initiative and creativity of cadres. This is critical. Because the purpose of assessment is to honor rewards and punishments, otherwise, it will lose the significance of 
assessment work. Rewards and punishments can be divided into economic rewards and punishments and job rewards and punishments. Judging from the practice in recent years, economic rewards and punishments are suitable for one-time cash payment and are not suitable for promotion of wages. Promotion salary can not reflect the strong stimulation and competition, and it can not attract people's attention. If the implementation of one-time rewards and punishments is different, the effect will be greatly changed. In the economic rewards, not only the implementation of reward for outstanding cadres; and incompetent cadres to resolutely punish and deliver basic fit, so as to reduce the financial burden of cash incentives, but also can enhance the overall sense of responsibility and dedication of cadres. In terms of duty rewards and punishments, it can be carried out in conjunction with economic rewards and punishments, but must be based on the actual situation, can not be generalized, should be specific analysis of specific issues. In general, assessment is not appropriate to reward job rank promotion, because it itself is the assessment of the term, if it is linked with job promotion, it will inevitably appear "quick success and instant loss" and other undesirable phenomena. Of course, especially good can be used as a basis for promotion. But for those incompetent or competent cadres, as long as the assessment that caused not belong to objective factors, they should be given the dismissal, demotion, this is the effective way to solve the leading cadres sluggish exports.

Fourth, we should look at the work achievements of cadres in a comprehensive and correct manner. To enhance the accuracy of performance identification, we must dialectically analyze and evaluate the performance of the work. We should start with five aspects: first, the relationship between "empty achievement" and "real achievement". We must adhere to the two civilization together, the two results together to the principle of both the hard task of tangible, also can not ignore the invisible "soft index", "single head cannot care for this and lose that". Two is the relationship between the collective and the individual. According to the job responsibilities and division of labor, pay attention to the performance appraisal process, especially the subjective efforts of cadres, play a role in such aspects as to the focus of assessment, to correctly distinguish and evaluate the team collective and each member's performance, to prevent the emergence of a "performance" with performance and eat "big pot" phenomenon. At the same time, pay attention to distinguish responsibility, prioritize, prevent the occurrence of performance problems on the phenomenon or performance control. Three is the relationship between individual subjective effort and objective environment. We must pay attention to analyzing the objective conditions and basis for the cadres to carry out their work, and objectively and comprehensively analyze the causes of performance, so as to avoid simplification and unilateralism in performance appraisal. Four is the relationship between current performance and long-term development. Not only to assess the significant performance, but can not ignore the potential achievements, and pay attention to distinguish between the incumbent leading cadres and former achievements, not only to look at the current cadre of what has been done, and what is left to the successor, to lay a foundation for long-term development of what. The five is the relationship between the overall interests and the local interests. Examining and evaluating the performance of a team and a cadre should not only depend on the achievements achieved in the performance of their post duties, but also on whether they can stand up to the overall situation and maintain the overall situation.

\section{Innovative Assessment Methods, So That Leading Cadres of Party and Government Assessment of Normalization and Standardization}

Increase daily assessment, regular assessment and assessment at ordinary times. Assessment at ordinary times can be used for regular assessment of the accumulation of materials, providing 
information, and contribute to a comprehensive, historical and objective evaluation of cadres. Therefore, the daily assessment of leading cadres should be strengthened, and the registration system for Cadres' performance should be actively implemented in the county level section and leading cadres and the quarterly registration cards shall be uniformly printed by the county Party committee. According to virtue, ability, diligence, performance, price and so on, it is filled in by the leading cadre himself. At the end of each quarter, the supervisor will review and fill in the opinions and file it as the basis for the year-end review and periodic assessment. At the same time, the Organization Department of the county Party committee should devote enough energy to strengthen the assessment of the leading cadres at ordinary times, and the staff responsible for the assessment should guarantee $1 / 3$ of the time each year to understand the situation at the grassroots level. We should promptly collect information and reflection from the media, discipline inspection, supervision, letters and visits, and effectively implement the usual understanding and assessment of leading cadres, and lay a good foundation for regular assessment.

Put integrity into the assessment system, establish personal integrity files. The government is the national credit representative, the party and government leading cadre is the policy maker of the government concrete administrative behavior, the government credit behavior has the demonstration effect in the society. According to the credit of the government in policy, law enforcement injustice, "three" and other issues, leading cadres to effectively change their work style, change from management to service, do not offside, dislocation, vacancy, all according to law and according to law; establish a strict scientific system of government procurement, reduce procurement waste and corruption; the implementation of Party and government organs and staff welfare money and wealth publicity system; strengthen the "accountability system" and "one vote veto" responsibility, causing serious damage and harm the decision on the "wrong", should be held accountable; establish a scientific performance evaluation system, to prevent some party and government cadres to engage in formalism, do specious writing. Through the public security, banks, schools, social organizations, private social circle etc. the integrity of records of leading cadres personal; at the same time, the leading cadres of the party and government, the academic evaluation, examination and assessment phase up to those who resort to deceit, with no credit; no, not blind foolhardy to give "class". "People who are trustworthy, without a letter possession, no political letter will be decadent", only the formation of a good atmosphere for everyone is honest and participate in the construction of credibility, to the healthy development of socialist market economy. The examination of leading cadres of the party and government can reflect objectivity, fairness and truth.

Further improve the quality of the assessment, to ensure that the results of the examination objective and impartial. The quality of assessment is closely related to the quality of the examiners themselves. The functions and responsibilities of leading cadres and leadership of the different assessment in evaluation object is complex, want to be able to accurately evaluate the leadership and leading cadres, not only need to have a higher level of policy theory and the art of conversation, also need to have relevant business knowledge. But in fact some of our assessment because of the knowledge base is not solid, working experience is single, plus the usual lack of necessary basic quality training, do not meet the needs of the assessment work, so that the quality and level of assessment work is affected. We should constantly improve the political and professional quality of the assessment personnel. The organization department should pay attention to those comrades who have good basic quality, have development potential, have certain practical experience, and be able to do the work of cadres to the assessment team. Assessment personnel should strive to master the theory of socialist market economy and relevant knowledge about economic work and Party building, and be able to observe and identify cadres in a dialectical way. 


\section{Reference:}

[1] Zhang Qin,.21. Conception and basis of quality model of Party and government leading cadres in the 21st century [J]. Journal of Beijing Administrative College, 2000.6.

[2] Wei Lan. Research on the evaluation system of Party and government leading cadres from the perspective of rationalization [J]. Trade Union Forum, 2008.3.

[3] CPC Heilongjiang municipal Party Committee Organization Department of Fujin research group. Efforts to build a new scientific talent selection mechanism [J]. leadership of science 2007.23.

[4] Shao Feng. Elimination of information asymmetry: perfect cadre assessment mechanism, [J]. party and government forum, 2007.2. 